Revue

Revue de l'histoire des religions

de Ihistoire des religions

3 | 2017

Varia

Frédéric GugeLoT, La Messe est dite. Le Prêtre dans la littérature d'inspiration catholique au $\mathrm{XX}^{e}$ siècle

Rennes, Presses Universitaires de Rennes, («Interférences »), 2015

Jean-Baptiste Amadieu

OpenEdition

Journals

Édition électronique

URL : http://journals.openedition.org/rhr/8807

DOI : $10.4000 /$ rhr.8807

ISSN : 2105-2573

Éditeur

Armand Colin

Édition imprimée

Date de publication : 1 septembre 2017

Pagination : $572-574$

ISBN : 978-2-200-93127-8

ISSN : 0035-1423

Référence électronique

Jean-Baptiste Amadieu, « Frédéric Gugelot, La Messe est dite. Le Prêtre dans la littérature d'inspiration catholique au xxe siècle », Revue de l'histoire des religions [En ligne], 3 | 2017, mis en ligne le 01 septembre 2017, consulté le 06 janvier 2021. URL : http://journals.openedition.org/rhr/8807 ; DOI : https://doi.org/10.4000/rhr.8807

Ce document a été généré automatiquement le 6 janvier 2021

Tous droits réservés 


\title{
Frédéric GuGELOT, La Messe est dite. Le Prêtre dans la littérature d'inspiration catholique au $\mathrm{XX}^{e}$ siècle
}

\author{
Rennes, Presses Universitaires de Rennes, («Interférences »), 2015
}

Jean-Baptiste Amadieu

\section{RÉFÉRENCE}

Frédéric GugeLOT, La Messe est dite. Le Prêtre dans la littérature d'inspiration catholique au XXe siècle, Rennes, Presses Universitaires de Rennes, («Interférences »), 2015, $21 \mathrm{~cm}$, 194 p., $18 €$, ISBN 978-2-7535-3615-9.

Comment composer des œuvres littéraires à la fois chrétiennes et de qualité ? Selon Frédéric Gugelot, les écrivains catholiques $d u \mathrm{xIx}^{\mathrm{e}}$ et surtout $\mathrm{du} \mathrm{xx}^{\mathrm{e}}$ siècle relèvent ce défi en introduisant dans leur roman un personnage de prêtre pour en analyser les luttes et les drames. Mais une telle expérimentation varie d'une œuvre à l'autre; Henry Bordeaux (dans La glorieuse Misère des prêtres, Paris, Flammarion, 1928, p. 152, cité par F. Gugelot p. 29) voit le curé comme un «grand barrage spirituel contre la montée des appétits et des convoitises fatalement déchaînés par le progrès matériel et par l'envahissement des villes aux dépens de la saine et paisible vie agricole ", quand Mauriac (Qu'attendez-vous du prêtre?, Paris, Plon, 1949, p. 12, cité p. 57) se représente, de son côté, les ministres sacerdotaux comme « les seuls vrais poètes, les seuls qui aient choisi l'absolu, qui bien plus que Rimbaud et que toutes les idoles des garçons d'aujourd'hui se soient séparés du monde ». Le principal mérite de ce travail consiste à proposer une typologie des littératures d'inspiration chrétienne. Barbey, Bloy, Bourget, Bordeaux, Bernanos, Mauriac, Cesbron, Michel de Saint-Pierre créent chacun des univers fictionnels et religieux bien différents, sinon antagonistes (songeons aux diatribes de Bloy contre Bourget). La qualification «catholique " accolée à tel ou tel roman a parfois soulevé de fortes divisions au sein de la critique confessionnelle, en 
particulier durant l'entre-deux-guerres. La Messe est dite permet d'y voir plus clair dans le brouillard de ces polémiques internes au monde catholique.

2 Frédéric Gugelot distingue en effet deux grands types de littérature, l'une dite " de l'ordre et de la morale ", attachée à l'affirmation identitaire et à l'édification; l'autre «de recherche spirituelle», «de communion» ou encore "d'Incarnation». La première, plus politique et sociale, réagit à la sécularisation de la société et milite contre l'effondrement du pouvoir religieux; la seconde privilégie les questions spirituelles. Si littérairement la veine de l'ordre se revendique de Balzac alors que le roman de la quête intérieure s'inscrit dans la filiation de Dostoïevski, théologiquement elles mettent l'accent sur des convictions distinctes. Hantée par le péché originel et la décadence de la société, la littérature de l'ordre affiche sa fascination pour l'institution ecclésiale, rempart dressé face aux déliquescences contemporaines. De son côté, la bataille qu'entend mener la littérature de communion ne se livre pas contre le monde moderne, mais contre les puissances du mal en un combat spirituel; elle s'attache plus à la Rédemption et aux valeurs évangéliques qu'au combat politique. Aussi son héros sacerdotal s'impose-t-il comme un apôtre ou un martyr, du moins comme un éveilleur spirituel, plutôt que comme le pasteur des ouailles prôné par la veine de l'ordre.

3 La typologie n'est pas seulement littéraire ou théologique; en historien, Frédéric Gugelot analyse le contexte dans lequel s'épanouissent ces deux veines. La littérature de l'ordre connait son plein essor dans les années 1880-1910, en un temps de menaces pour l'Église, de sa séparation à marche forcée avec l'État, en un temps de mentalité de la « citadelle assiégée ». René Bazin, Louis Bertrand, Paul Bourget, Émile Baumann et Henry Bordeaux participent au mouvement de défense de l'Église, et plus généralement de la société traditionnelle, du bon sens rural face aux artifices maladifs de la vie citadine, de la famille fondée sur le mariage sacramentel et indissoluble : ils « offrent aux lecteurs une littérature traditionaliste, régionaliste, rempart de la religion et d'une société d'ordre moral et social. Les prêtres de papiers y sont des combattants promus par des écrivains organiques » (p.39). Cette littérature s'adresse à un public déjà conquis; elle le confirme dans ses choix politiques et religieux et ranime le courage dans la mêlée. La condamnation de l'Action française en 1926 brise cet élan littéraire désireux d'une société éduquée par l'Église ; la voie est libre pour qu'un autre souffle supplante l'inspiration de l'ordre.

4 La veine spirituelle s'adresse à un public nouveau, dans un contexte différent. Les écrivains catholiques des années 1930-1950 prennent acte de la sécularisation; ils s'attribuent la mission de convertir, élargissent leur audience aux lecteurs éloignés de toute vie religieuse, et campent leur prêtre en un inspiré à la parole prophétique. Le prêtre bernanosien, par exemple, prend conscience que la Chrétienté, la paroisse, le village à l'ombre du clocher, sont des idées désormais hors d'atteinte; le curé échoue à créer une authentique communauté chrétienne. Chez Mauriac, il n'est plus que l'instrument lamentable de la grâce. Ce nouveau type de prêtre se débat avec ses drames personnels plus qu'il guide le troupeau. À partir des années 1950, on s'adresse plus particulièrement au prolétariat à rechristianiser. Les prêtres-ouvriers deviennent les héros de romans aux passages obligés: la messe sur une table de cuisine, la participation aux défilés protestataires, le conflit avec le clergé institutionnel végétant " entre le bedeau, la chaisière et deux vieilles " (Cesbron, Les Saints vont en enfer, cité p. 92). Mais en 1964 le roman de Michel de Saint-Pierre Les Nouveaux Prêtres, qui se prétend une enquête sur le modèle de Cesbron, déchaîne les passions; les pages que 
Frédéric Gugelot lui consacre (p. 135-149) sont d'autant plus intéressantes qu'elles sont éclairées par les archives privées des Saint-Pierre. Le romancier, fidèle à la tradition contre-révolutionnaire mais dans le contexte du Concile, de l'Algérie française, de l'antigaullisme de son éditeur (la Table ronde), poursuit la veine de l'ordre, dénonce la décadence de la société et d'une partie du clergé lui-même; la littérature de défense identitaire se maintient donc au-delà de la République anticléricale.

Car l'étude de Frédéric Gugelot, si elle formule une distinction efficace entre deux littératures catholiques, ne sombre évidemment pas dans les travers propres aux typologies systématiques tentées de ne sélectionner que les données probantes. D'abord parce qu'il distingue plusieurs tendances au sein des deux littératures; par exemple, la veine de l'ordre compte d'un côté une défense des sociétés rurales (Bazin, Bordeaux), et de l'autre une promotion des valeurs bourgeoises (Bourget), assez peu compatibles entre elles. Ensuite et surtout, les études de cas présentées dans l'ouvrage montrent la complexité des situations. S'il distingue ainsi les deux veines selon la préférence donnée au clergé séculier ou régulier (la littérature de l'ordre adule le curé de paroisse, que les romanciers spirituels jugent ignare et mondain, lui préférant le moine censé vivre la foi dans sa plénitude, voir p. 34), il livre au lecteur un jugement de Mauriac qui nuance une telle distinction: le prêtre séculier, écrit le romancier dans Commencements d'une vie (1932), a "renoncé quelquefois à la vie religieuse par sacrifice et comme à un luxe (ainsi fit le curé d'Ars)», cité p.51. Ou encore, il cite l'abbé Donissan de Sous le soleil de Satan voyant ressurgir le «dogme catholique du péché originel» (cité p. 49), qui imprègne pourtant davantage la littérature de l'ordre. La classification débrouille le tableau confus de la littérature catholique, sans occulter la fragilité des frontières (Psichari célèbre à la fois l'ordre et les vertus initiatiques du désert) et les limites des périodisations. À ce sujet, l'auteur éclaire judicieusement son objet en remontant au-delà de sa période, à Barbey et même à Chateaubriand et à de Maistre. Son abondante documentation primaire et secondaire exhume des textes peu connus, comme la « Préface » aux Critiques et études littéraires de Charles de Rémusat qui s'est inquiété, dès 1850, d'une littérature chrétienne seulement de nom.

6 L'ouvrage trouve un bon équilibre entre les études de cas et les six chapitres qui charpentent l'analyse en autant de périodes, de 1885 à 1980. L'introduction met en perspective le sujet en remontant au début du XIX ${ }^{\mathrm{e}}$ siècle ; elle s'interroge sur l'idée de littérature chrétienne, en délicatesse à la fois avec l'orthodoxie catholique et le champ littéraire, et sur les héros sacerdotaux de romans, à la croisée de la transcendance et de l'humanité. La conclusion récapitule les principaux points de divergence entre les deux types de littérature chrétienne. Ce précieux outil de travail, pourvu d'une bibliographie et d'un index nominum, prend désormais place parmi les études de référence sur la littérature catholique du $\mathrm{xx}^{\mathrm{e}}$ siècle. 


\section{AUTEURS}

\section{JEAN-BAPTISTE AMADIEU}

Centre national de la recherche scientifique

(République des savoirs). 